\title{
Moral Responsibility, Culpable Ignorance and Suppressed Disagreement
}

\section{Introduction}

Agents can draw on ignorance as an excuse for otherwise blameworthy action, but only if they are blameless for their ignorance. One way to avoid culpable ignorance is to pay attention when your epistemic peers disagree with you. Expressed disagreements place an obligation on the agent either to pay attention when an interlocutor disagrees or risk culpable ignorance for which they might later be found blameworthy. On the other hand, agents are typically permitted to take silence as assent. But in cases of suppressed disagreement, silenced interlocutors have information that could save the agent from ignorance and resultant harmful action. In these cases, silence does not actually indicate assent. The worry that agents are typically permitted to take silence as assent and that this can lead to harmful consequences in suppressed disagreement cases, is further complicated because the agent might not be aware that suppression has occurred. In this paper, I provide a new account of excuses from ignorance in situations of suppressed disagreement. I develop this account using two cases; Kelly's (2005) hypothetical case of the Tyrannical Dictator, and the real-world case of former South African President Thabo Mbeki and his AIDS denialist policies in the late 1990s and early 2000s.

This paper is structured as follows. I begin by explaining the relationship between moral responsibility, culpable ignorance and disagreement, and I introduce the problem of suppressed disagreement. I then look at the standard philosophical response to examples of suppressed disagreement, which has been to distinguish between cases of actual disagreement (disagreement that someone has actually expressed) and merely possible disagreement (disagreement that has not been expressed by anybody, but is possible in the modal sense - there is a possible world in which an interlocutor disagrees). However, as has been correctly pointed out in the literature, giving epistemic weight to merely possible disagreement leads to strange consequences and should be avoided. Instead, I propose distinguishing between expressed disagreements, and suppressed actual disagreements 
(instances in which someone does actually disagree with the agent but has been unable to express that disagreement due to suppression). I argue that in certain circumstances there will be markers that suppression has occurred (such as silence when one would expect there to be debate). Depending on the context, and the role of the agent in that context, the agent will have an obligation to be on the lookout for the markers of suppression. Further, if the agent is also responsible for suppressing the disagreement in the first place, they will be additionally blameworthy for having done so.

\section{Moral Responsibility, Culpable Ignorance and Disagreement}

When you undertake an action with harmful consequences you might be found blameworthy for it. Being blameworthy, on at least one popular account, means that we can legitimately adopt certain negative reactive attitudes toward you - such as anger, resentment, and disappointment (Strawson, 1962/2008) - and that it would be appropriate for you to adopt negative reactive attitudes toward yourself - such as regret, guilt, and remorse (Williams, 1981 ; Fischer \& Ravizza, 1998, pp. 5-7; Levy, 2005, p. 2).

Blameworthiness is distinct from merely being accountable for your actions. Accountability tracks whether the harmful action can be causally attributed to the agent, while blameworthiness tracks the appropriateness of adopting negative reactive attitudes towards them. If you put arsenic in my tea and it kills me, then you are accountable. However, agents can frequently draw on an ignorance as an excuse for otherwise blameworthy action (Rosen, 2004, p. 298; Smith, 1983; Zimmerman, 1997; Strawson, 2008, p. 3; Aristotle, NE1113b24-16; Peels, 2017). For instance, if the sugar in your sugar bowl underwent a freak chemical transformation that created the arsenic, and you did not know that this had occurred when you put it into my tea, then you would not be blameworthy for my death. However, you can only successfully use ignorance as an excuse so long as you are not also blameworthy for that ignorance. If you had been storing arsenic in your sugar bowl and had just forgotten about it when preparing my tea, then your ignorance is blameworthy (because it is the result of negligence) and so you cannot use it as an excuse for your action. It does not get you off the hook. ${ }^{1}$

\footnotetext{
${ }^{1}$ The arsenic case is taken from Rosen (2004, p. 399-400)
} 
You can avoid culpable ignorance by satisfying your 'procedural epistemic obligations'. This is the requirement that you should take due care when forming beliefs that inform actions with foreseeable harmful consequences (Rosen, 2004, p. 301). In Rosen's words:

Now among the required precautions against negligent harm are certain epistemic precautions. As you move through the world you are required to take certain steps to inform yourself about matters that might bear on the permissibility of your conduct. You are obliged to keep your eyes on the road while driving, to seek advice before launching a war and to think seriously about the advice you're given; to see to it that dangerous substances are clearly labelled, and so on. These obligations are your procedural epistemic obligations... As I understand them, these procedural obligations are always obligations to do (or to refrain from doing) certain things: to ask certain questions, to take careful notes, to stop and think, to focus one's attention in certain directions, etc. The procedural obligation is not itself an obligation to know or believe this or that. It is an obligation to take steps to ensure that when the time comes to act, one will know what one ought to know (2004, p. 301).

One way to take care when forming your beliefs is to pay attention when an epistemic peer - someone with similar levels of reasoning ability and access to evidence as you (Kelly, 2005, pp. 173-174) - disagrees. For instance, imagine that you are a high-ranking member of the army trying to decide whether to bomb a site and you have a thermo-imaging map to help you make the decision. You notice that there is a warm spot to the side of the map and conclude that the heat pattern is consistent with there being a weapons manufacturing plant in that location. Your colleague, who has the same training as you and is looking at the same map, disagrees and suggests that the heat pattern is also consistent with the site being a hospital. You should pay attention to what your disagreeing colleague has to say. Otherwise, you risk being culpably ignorant and morally blameworthy if things go very badly wrong (in this case, if it turns out that it was really a hospital and not a weapons factory).

Now consider a completely different case. A tyrannical dictator kills off any would-be dissenters before they have a chance to disagree with him. On some particular issue there would have been considerable disagreement, but because everyone who would have disagreed is now dead, there is nobody to give expression to that disagreement (Kelly, 2005, pp. 181-182). We can imagine that the dictator undertakes some harmful action (completely independently of his initial killing of the would-be dissidents) on the basis of a belief that went uncontested. However, as noted above, agents can make use of ignorance as an 
excuse for seemingly blameworthy action. Perhaps he did not know that the action would have the harmful consequences that it did. When we assess whether the dictator's ignorance was blameworthy, the dictator might argue that he satisfied his procedural epistemic obligations by looking for disagreeing interlocutors and that none were forthcoming (because everyone who would have disagreed is dead). Would we be convinced by his excuse from ignorance? It seems unlikely that we would, or that we should. ${ }^{2}$

Now consider a real-world case, which shows what is at stake in ways that the hypothetical cases cannot. In the late 1990s and early 2000s, then South African President, Thabo Mbeki, endorsed the position of fringe scientists that HIV does not cause AIDS, and that antiretrovirals (ARVs) - the treatment that prevents the virus from replicating - is toxic. As a result, he prevented the distribution of ARVs via the public health system. This policy persisted until 2004, with severe consequences. Best estimates indicate that it resulted in 171,000 avoidable new infections and 343,000 deaths over the $1999-2002$ period (Nattrass, 2008, p. 157). Other senior members of his political party, the ANC (African National Congress), disagreed with him and could have saved him from ignorance, but they were too afraid of him to do so, due to his arrogant approach to interlocutors (Steinberg, 2017 ; Feinstein, 2007). Importantly, members of the ANC occupied a unique position of moral credibility in this case. Mbeki distrusted members of the mainstream scientific community and the international press, both of which did actually express disagreement (Durban Declaration ,2000; Herbst, 2005; Johnson, 2007), because he suspected them of racism (Anonymous, 2002). By contrast, members of the ANC who had fought alongside Mbeki against apartheid, the racist regime that governed South Africa until 1994, were not subject to the same suspicion and their disagreement could have really made a difference. Should their silence provide Mbeki with an excuse from ignorance when assessing whether

\footnotetext{
${ }^{2}$ Some readers might not be convinced by this case. They might be concerned that our intuitions about blameworthiness for ignorance are sullied by our intuitions about blameworthiness for killing. I am hopeful that these readers will find the next case more compelling, where there is no mass-murder to taint their response. It is important to include the tyrannical dictator case, regardless of whether all readers have the same intuitive response to it, because it has been the springboard for much of the subsequent literature on this topic.
} 
he can be held personally morally responsible for the extremely harmful consequences of his policy decision?

Cases of suppressed disagreement, like that of the tyrannical dictator and Mbeki, are puzzling. Recognised expressed disagreement from one's epistemic peers creates an obligation to pay attention to that disagreement (Christensen, 2007 ; Feldman, 2006 ; Elga, 2007). And we often take silence in response to our assertions as an indicator of agreement (Goldberg, 2016). But taking silence as agreement in cases of suppressed disagreement has troubling outcomes. The implication is that if we were able to silence potentially disagreeing interlocutors before they have a chance to actually express disagreement, that would make our ignorance less culpable and our resulting actions less blameworthy. Or as Lammenranta phrases the problem: "[t]his would mean that we could gain knowledge by killing our opponents" (Lammenranta, 2011, p. 211). Presumably, he means so long as we manage to kill off our opponents before they have a chance to express their disagreement. This is clearly the wrong outcome. But of course, a great deal depends on the details of the case. If the agent suppresses the interlocutor at the very moment that they begin to express disagreement, because they can see that they are about to receive unfriendly testimony, then the jigs up and there is no way that they could appeal to ignorance as an excuse. However, there are many cases in which the suppression is subtler than this, and this requires us to think more carefully about how we should take account of epistemic peers.

\section{Is there a distinction between actual and merely possible disagreement?}

In this section I provide an outline of the debate that has arisen in response to Kelly's example of the tyrannical dictator. In particular, the question of whether 'merely possible disagreement' should be afforded the same epistemic significance as 'actual disagreement'. If it is the case that possible disagreement is as epistemically weighty as actual disagreement, then this would solve the challenge posed by the cases of the tyrannical dictator and Mbeki. In both cases, if merely possible disagreement were as epistemically important as actual disagreement, then they should have been on the lookout for possible disagreements with their view; they were not, and so their ignorance is culpable and they are blameworthy. However, as will be seen, this route out of the problem is not available. 
Kelly takes his example of the tyrant to indicate that there is no distinction between actually articulated disagreement and merely possible disagreement. What matters for determining whether a disagreement should threaten one's existing beliefs, he argues, is the strength of the arguments and the evidence put forward in support of that disagreement - regardless of whether the disagreement is actual or merely possible. As such, the disagreement itself is irrelevant and one should focus on the arguments and evidence that could be levelled against a particular belief, not the disagreements themselves (Kelly, 2005, pp. 181-182).

The way that Kelly sets up the argument leaves us with something of a dilemma. Kelly uses the case of the tyrannical dictator to argue that there is no difference between merely possible disagreement and actual disagreement, which in turn he uses to cast doubt on testimony as a form of evidence - it is not the testimony that matters, it is the underlying arguments and evidence that matter. If we side with Kelly, then it is unclear why an agent would have any obligation to pay attention to disagreeing interlocutors, because testimony (in general) is not a form of evidence, and disagreement (a particular type of testimony) does not matter. At first glance, this leaves us at a loss for how to deal with a large portion of cases that seem like they should be instances of culpable ignorance. Kelly might argue that in these cases the agent should have thought about whether someone would have good reasons for dissent, but he places a lot of faith in the abilities of ordinary epistemic agents to anticipate all the possible reasons for dissent and treat them with appropriate weight. That is, he places a lot of faith in the agent to recognise all possible disagreements. If we want to resist Kelly (and hang on to the position that neglecting peer disagreement is a route to culpable ignorance), then it seems that we need to reject the claim that actual disagreement and merely possible disagreement are on par. But then we lack the resources to deal with the tyrannical dictator and Mbeki cases. Even though Kelly's position is plausible - it is the arguments and the evidence that matter, not the testimony itself - he asks too much of reasoners that they anticipate all counter-examples. Testimony continues to have an important role to play. In this section I focus on the other horn of the dilemma. I argue that actual disagreement and merely possible disagreement should not be put on a par, but also that this does not strip us of the intellectual resources to deal with the tyrannical dictator and Mbeki cases. 
In the rest of this section I consider two arguments that have been put forward in response to Kelly: 1) accepting the position that actual disagreement and merely possible disagreement are as epistemically weighty as each other results in unacceptable scepticism (the Sceptical Argument); 2) actual disagreements provide a signal that an error may have occurred and merely possible disagreements cannot do this (the Signalling Argument), and so Kelly is wrong to put them on a par.

The Sceptical Argument tells us that if actual disagreement and merely possible disagreement were on par, this would put us in an untenable philosophical position, because for any belief that one might have, there is always a possible disagreeing interlocutor. For any $\mathrm{P}$, there is a possible interlocutor who holds that $\sim \mathrm{P}$. Taking into account all possible disagreements would require that we suspend (or substantially revise or diminish our confidence in) all of our beliefs, resulting in widespread scepticism (Kornblith, 2010, p. 34; Carey, 2011 , pp. 374-377). It should be noted that Kelly's position does not commit him to the sceptical conclusion. As explained above, Kelly argues that disagreement is irrelevant, which means that no one is required to alter their beliefs in the face of actual disagreement or merely possible disagreement, so he avoids the sceptical conclusion. But regardless of what Kelly himself is committed to, it is still worth considering the implications of taking merely possible disagreement as seriously as actual disagreement, because if this were the case then it would provide a solution to the problem of suppressed disagreement.

One way of taking merely possible disagreement seriously, without falling into the trap of scepticism, is to consider possible disagreements only in nearby possible worlds. This amounts to engaging in some abstraction from the actual world, but not considering disagreement from all possible worlds, thus evading the problem that there is always some possible world in which an interlocutor disagrees. Barnett and Li (2016) offer a related suggestion, based on appropriately selecting the sample of nearby possible worlds probabilistically, such that only the most likely sources of disagreement should count. The approach of only considering nearby possible worlds is appealing and coheres with some common-sense views about what one ought to do when considering potentially harmful action. Dryzek and Niemeyer (2008) advocate for something similar when they argue that 
that deliberative democracy requires that all relevant viewpoints be considered when making a decision, not just those that are actually represented:

Rationality may even benefit from the presence of a vantage point to which nobody subscribes; such was presumably the rationale for the use of a "Devil's Advocate" when evaluating cases for sainthood in the Catholic Church (Dryzek \& Niemeyer, 2008, p. 482)

Considering disagreement from nearby possible worlds amounts to taking into account viewpoints that may not actually be represented at the decision-making table, but which bear on the issue under consideration, and this looks like very sensible advice. For instance, we can imagine that a committee needs to make a decision that will affect the homeless community in the city. They discuss a proposed policy, but there are no homeless people in the room to express their disagreement with a proposed policy, and the homeless community has no one to represent their views to the committee. In these circumstances, it would be good for the committee members to imagine what disagreements the homeless community might have with the proposal, even though there are no actual homeless people in the room to give expression to their viewpoint. This is the same as (or very close to) considering a nearby possible world in which there is a homeless person in the room to give expression to the dissenting view. While this would be a good thing to do, we now seem to have strayed from the realm of disagreements.

What is going on when you consider disagreements from nearby possible worlds? Given that you are acting as your own disagreeing epistemic peer in this scenario ${ }^{3}$ - you have the same reasoning ability and the same evidence as you actually have - considering disagreements from nearby possible worlds amounts to carefully thinking through the evidence that you already have. It therefore looks like taking account of disagreements from nearby possible worlds just means that you should think really hard before engaging in actions with potentially harmful consequences, and this was already covered by the advice provided by Rosen earlier in this paper, when his stance on procedural epistemic obligations

\footnotetext{
${ }^{3}$ This is not a necessary requirement of the position that one should take account of disagreement from nearby possible worlds. However, this is the practical result of such a recommendation, given that the agent does not actually have access to nearby worlds and can only construct what the possible disagreements would be on the basis of the evidence they already have available to them.
} 
was described. He advises that satisfying one's procedural epistemic obligations requires that one ought "to stop and think, to focus one's attention in certain directions..." before engaging in an action that could have foreseeable harmful consequences (Rosen, 2004, p. 301), and so advising that one should consider disagreements from nearby possible worlds does not add anything useful. Considering only nearby possible worlds does not provide us with a route out of the Sceptical Argument, because we have changed the case too much we are no longer really dealing with actual/possible peer disagreement. ${ }^{4}$

Another way of dealing with the Sceptical Argument would be to bite the bullet and accept the sceptical conclusion. Ballantyne (2015) does something similar when he suggests that we should be epistemically modest about almost all of our most interesting beliefs, due to existing, but unpossessed, evidence that runs counter to them. Ballantyne's argument goes like this. We live in an era of information glut. As such, it is very likely that for any interesting belief that you hold, you have only a small portion of the relevant evidence. Amongst the evidence you don't possess, it is likely that someone has made a good argument with good evidence against your view. Even if you don't yet know the content of the dissenting argument, you know that it is likely to exist and that it is likely that at least some of the dissenting arguments are compelling. He suggests that all you need to do is walk through your nearest university library to see that for many of your beliefs there are a wide variety of books that have been written on the topic, many of which go against your view. This problem is augmented if you do a Google Scholar search. His suggestion is that the appropriate reaction to this realisation is that you should be epistemically modest about many of your beliefs, by which he means that you "should reduce confidence" in them (p.317). Note that Ballantyne's argument doesn't require us to downgrade confidence in all of our beliefs. For instance, beliefs with almost unanimous agreement will not be affected, because there is no reason to think there is compelling dissent amongst the unpossessed

\footnotetext{
${ }^{4}$ Considerations of nearby possible worlds links to the distinction between recognised and unrecognised possible disagreements. I have been using the term 'merely possible disagreement' as if to cover both, but it is really only unrecognised possible disagreements that cause the trouble. It isn't true that there is always a recognised possible disagreement that can undermine your view. However, cases of recognised possible disagreement, like the suggestion to consider disagreement in only nearby possible worlds, do not seem to be cases of disagreement at all. Cases of recognised possible disagreement are just cases in which the agent recognises that they have evidence and arguments that are contrary to their view, and so the 'possible disagreement' is not doing work at all
} 
evidence. I am, for example, not concerned that a stroll through my university library will provide me with reason to suspect that there is compelling dissent against my belief that the world is round (because this is a belief that is widely agreed upon). However, I do think that if I wander over to the Social Sciences section I am likely to encounter arguments against my current belief that microloans reduce poverty in developing countries.

Ballantyne offers us a more palatable version of the sceptical conclusion, but his argument still does not help us very much with the cases that have motivated this paper - that of the tyrannical dictator, or with the Mbeki case - because his hypothetical agent is in a very different epistemic position to the kinds of agents we are considering. In Ballantyne's cases, the disagreements have been actually expressed (people have written books and articles on the relevant topics, those books have been published and put in the library, the articles have been catalogued and put on Google Scholar), and the agent knows that they have been expressed (they have browsed the university library, and they have done a Google Scholar search); she just doesn't yet know what the content of the disagreement is. This is different from the dictator and Mbeki cases, in that disagreement from epistemic peers did not have a chance to be actually expressed in either of case.

Ballantyne offers a different version of this argument in Counterfactual Philosophers (2014) which might help on this issue. Here he argues that we should be modest about many of our philosophical beliefs because we know that the composition of our philosophical communities is fragile. Had different philosophers existed, we would have different arguments and objections available to us. In the case of counterfactual philosophers, the possible interlocutors did not have a chance to express their disagreements (like the interlocutors in the tyrannical dictator and Mbeki cases), because they did not exist. But again, this isn't helpful to the cases we are considering. Ballantyne takes the point to be obvious; "[w]e know all about counterfactual philosophers - those who could have been working among us now but are not" (p. 368). By contrast, it is unclear whether the dictator and Mbeki are aware that there is disagreement that has been suppressed. So, while Ballantyne offers us a plausible way of accepting something akin to the Sceptical Argument - that we should be epistemically modest about most of our beliefs - he does not offer us a way out of the Sceptical Argument in a way that is helpful to our motivating cases. 
Another argument for why actual disagreement should not be put on an epistemic par with merely possible disagreement is that actual disagreements give us information that merely possible disagreements may not - this is the Signalling Argument (Tersman, 2013 ; Carey, 2011 ).To see how this argument works it is helpful to take a step back and note that the reason conciliationists - those who think that we are required to revise or reconsider our beliefs when we discover that an epistemic peer disagrees with our view - believe we should take disagreements seriously is due to a kind of inference to the best explanation. Having a disagreement with someone who is as competent at reasoning as I am and has access to the same evidence that I do indicates that one of us has made an error, but we cannot tell from the mere fact of disagreement which one of us has erred. Sidgwick makes this point as follows:

For if I find any of my judgements, intuitive or inferential, in direct conflict with a judgement of some other mind, there must be some error somewhere: and I have no more reason to suspect error in the other mind than in my own... (Sidgwick, 1981/1907, p. 342).

Christensen's (2007) famous dinner bill case makes this particularly clear. ${ }^{5}$ Christensen asks us to imagine a scenario in which friends go out for dinner, an activity that they frequently participate in. At the end of the meal, two friends figure out how to split the bill. They are equally good at the kind of arithmetic that is required to perform the task and they both have the same evidence (the bill), but they come up with two slightly different amounts at the end of their calculations. It is clear that one of them has made an error, but it is not clear just from their disagreement which one of them it is (Christensen, 2007, p. 194). Their disagreement has provided them with evidence of a mistake. That there is some possible world in which someone disagrees with a particular belief does not give the agent any new evidence (Carey, 2011 , p. 378). Merely possible disagreement does not serve the signalling function that actually expressed disagreement does, and so it should not be given consideration in the way that we give actual disagreements consideration.

\footnotetext{
${ }^{5}$ Both Kornblith (2010) and Carey (2011) use this example to make a similar point to what I make here.
} 
I find both the Sceptical Argument and the Signalling Argument convincing. It does seem that failing to distinguish between the epistemic significance of actual and merely possible disagreement results in a scepticism so widespread that it cannot be acceptable (because there is always a possible world in which an interlocutor disagrees). Further, giving merely possible disagreement epistemic significance fails to recognise that the reason we give actual disagreements epistemic weight is because they provide us with evidence of potential errors.

However, accepting that merely possible disagreement should not be afforded the same epistemic significance as actual agreement, or any epistemic significance at all, does not mean that we are stuck with the conclusion that the tyrannical dictator and Mbeki are off the hook because no actual disagreement was forthcoming in their cases. To make sense of these cases we need to distinguish between "merely possible disagreement" (there is some possible world in which there is disagreement with my view) and "suppressed actual disagreement" (there is actual disagreement in this world, but that disagreement has not been expressed, because of suppression). While the former is not epistemically salient, the latter should be. Further, both the case of the tyrannical dictator and Mbeki are cases of suppressed actual disagreement, not of merely possible disagreement.

\section{Actual, but suppressed, disagreement}

There is still something puzzling about how instances of suppressed actual disagreement might be epistemically significant. In both of the cases that have motivated this paper-the tyrannical dictator and the Mbeki case - we can imagine that the agents did not know that disagreement had been suppressed. The tyrannical dictator might have killed off the potential dissidents without knowing that they would later go on to disagree with him (he had them killed for reasons other than their dissent). Mbeki might not have known that the members of his party feared him. In both of these instances, from the agent's perspective it might just look like nobody has disagreed and silence might (wrongfully) be interpreted as assent - this is clearly a more widespread problem. How then could suppressed disagreement be epistemically relevant if the agents do not even know that it is happening? Phrased slightly differently, suppressed disagreement does not give them any new 
information, much like the case of merely possible disagreement, and so it is unclear how suppressed disagreement could be of any epistemic relevance at all.

To get a grip on this issue, it will be helpful to better understand what a reasonable response to silence is. Imagine a case in which an agent makes an assertion, and is greeted only with stony silence in response - what would a reasonable interpretation of that silence be? Are they getting any information from the silence? Should they be getting any information from it? Answering these questions will help us understand what the obligations are on agents in cases of suppressed disagreement. In particular, if it turns out that the agent should be getting information from the silence (which I will argue that they should, in certain circumstances), then this distinguishes suppressed disagreement from merely possible disagreement, because the agent is actually getting information from the (silent) response, while they would get no new information cases of merely possible disagreement.

In what follows, I address only instances of literal silence. But there is clearly a range of related phenomena in contexts of suppression. In particular, there will be cases where those who are suppressed still make utterances, but in which they have been effectively silenced. For instance, when West and Langton (1999) talk about pornography "silencing" women, they do not mean that women are literally no longer permitted to speak. They mean that women are no longer properly heard when they speak (to use the appropriate technical language, their speech acts do not achieve "uptake") (McGill, 2013, p. 206). We can also imagine cases in which suppressed individuals explicitly assert assent, but only as a result of their suppression- when Kim Jong-un makes an assertion into a crowd in North Korea everyone will cheer regardless of whether they actually agree with what has been asserted. The members of the North Korean crowd have been effectively silenced, even though they are not literally silent. I will not be dealing with these more complicated cases here, but hopefully some of the lessons from the following discussion will also help to shed light on these other kinds of cases. For now, I will just address the question of what an agent should reasonably take from literal silence in response to their assertion.

Goldberg (2016) argues that we typically take silence in response to an assertion as assent: 
Among the possible explanations of another's silence in the face of mutually observed assertion, one stands out as particularly salient. This is the one according to which one's silence indicates one's assent to what was asserted (p. 97).

He also indicates that he endorses the position that the agent has a prima facie normative entitlement to take silence as assent (albeit an easily defeasible entitlement), but he explicitly does not argue for this position in this particular paper and notes that it is a controversial view to hold (Goldberg, 2016, p. 98). Tanesini (2016), by contrast, argues that a speaker has no normative entitlement to take silence as assent. On Tanesini's view, when a speaker makes an assertion they invite listeners to respond, but the listener is under no obligation to do so, even if they do not accept the content of the assertion. Because the hearer is under no obligation to offer a response, even if they disagree, the speaker is not entitled to take silence to be acceptance (Tanesini, 2016, pp. 7-8). For example, I might give a talk in the Philosophy Department, and none of the audience members will be obliged to express their disagreement with me during the question and answer period, even if they do actually disagree. If nobody raises their hand when it comes time for discussion, that does not mean that I am entitled to conclude that everyone in the audience agrees with everything I have said - a more plausible explanation might be that I was so boring that nobody can muster the energy to disagree with me by the time the opportunity becomes available.

Further, Beatty and Moore (2010) suggest that we should find complete consensus with some position to be suspicious. Complete consensus, they argue, might indicate that some coercion was involved. In explaining a comment by Elster (1986/1997), in which he argues that he would feel more comfortable passing a law that had a persistent minority opposed to it than one that had unanimous support, they say:

... [W] hat had worried him was the possibility that a unanimous decision might be due to some sort of conformism - perhaps resulting from intimidation, the suppression of alternative viewpoints, or self-censorship - rather than from a proper deliberation of the alternatives (Beatty \& Moore, 2010, p. 198).

They go on to say: 
...[N]o one expects unanimity in politics; not in light of culture, class, gender, and other differences. If a diverse voting body were to report unanimous agreement on an issue or candidate, one might well wonder if all the parties had freely spoken their minds (Beatty \& Moore, 2010, p. 199).

Further, silence in the literal sense, might be accompanied by body language that communicates that something is off. A suppressed silent interlocutor might avoid eye contact, they might turn away from the agent, or they might cross their arms over their body; amongst many other forms of body language we readily recognise as indicating that something is wrong. Andrew Feinstein (2007), for instance, describes what his own body language looked like as he sat literally silent in an ANC parliamentary caucus meeting on AIDS chaired by Mbeki. He tells us that he sweated profusely, avoided eye contact, pretended to type and furtively glanced at other members of the party that he knew agreed with him (p.126). Feinstein's physical responses signalled the discomfort of his silence, and we might expect a sensitive agent to have noticed these.

In summary, when an agent asserts something and receives silence as a response, this might indicate a range of things. Under some circumstances it might indicate assent, but in others it may just be that the listeners were too bored to respond, or that the disagreement had been suppressed. Listeners can have a range of reactions to an assertion and silence might mask some of those reactions. Or in some cases, the silence might be an expression of the reaction - such as might be the case when the listener is too bored to bother responding. Further, sometimes the body language of the interlocutor will be a signal to the agent of the type of silence that they are encountering.

In the second quote from Beatty and Moore above, they point out that silence is particularly suspicious in political environments, where we would expect there to be a wide variety of differing opinions and debates. When an agent makes an assertion about something in a political context and receives only silence in response, it seems like something strange is going on.

So far in this paper I have been treating the tyrannical dictator and Mbeki as though they were ordinary epistemic agents assessing their evidence in ordinary ways. In some sense, 
this is obviously the correct approach - an agent will only ever have the capacities of an ordinary epistemic agent (unless they are some kind of genius), regardless of the role that they occupy. However, it does seem that agents might have very specific epistemic obligations, depending on their social positioning - we expect medical doctors to keep abreast of recent developments in treatments, but we do not have similar expectations of epistemic agents in other roles (Peels, 2017, p. 101). Goldberg (2017) refers to this as an agent's 'role-specific obligations' (p. 2865). How one ought to react to silence in response to an assertion might vary depending on context and the role that the agent is playing in that context. It is plausible that bearers of political office, for instance, have role-specific obligations to pay attention when their assertions are greeted only with silence and to find this worrying. This would also extend beyond the political case. Longino (1990), in the scientific context, argues that various members of the scientific community are required to foster an atmosphere of free discussion and debate, precisely to avoid suppression of marginal views. Longino's position is more burdensome than what I want to argue for here, but it does show that the scope of the issue is not restricted to the political context.

Role-specific obligations also help us to understand why failing to be on the lookout for the markers of suppression can be culpable. To be sure, we don't expect all individuals to be constantly watching for suppressed disagreement. This is cognitively laborious and requires imagination. Further, as Goldberg (2017) points out, not all cases in which an agent should have known something (but didn't) will be cases of culpable ignorance. A very overworked social worker might miss the signs that a child is at risk, but it is the government department that failed to provide her with adequate resources, rather than social worker herself, that is to blame (Goldberg, 2017, p. 2889). However, when a paediatrician (in an appropriately resourced setting) fails to identify a common ailment in a child, her ignorance is culpable. Part of her role-specific obligation is to know certain things about common paediatric diseases and to be on the look-out for their markers. Similarly, the political decision maker who fails to notice markers of suppressed disagreement may be culpable for their ignorance, because part of their role-specific obligation might be to pay attention to that. This also helps us account for the relative culpability of agents at various levels of experience in their roles. We are less likely to find the junior doctor on her first day at work as culpable for failing to notice the markers of a common childhood ailment as the head of 
the paediatric unit who does the same. Similarly, we are less likely to find the newly elected politician in their first day of office as culpable for missing the markers of suppression as the well-seasoned politico.

This then deals with the problem of 'suppressed disagreement' associated with culpable ignorance, without falling into the sceptical conclusion. This is done by distinguishing suppressed actual disagreement from merely possible disagreement, in that the former sometimes carries information, while the latter does not. In particular, silence as a response sometimes counts as information or evidence of suppressed disagreement - this is true in cases where the normal response would not be silence, such as in political contexts.

Further, the body language accompanying silence (such as Andrew Feinstein's profuse sweating) might also be information bearing.

This then raises the question of how the silence came about in the first place. So far, the emphasis has been on the agent's responses to expressed disagreement and to silence. Nothing has been said about the blameworthiness of the agent relative to the circumstances that resulted in the disagreement being suppressed, and the two examples discussed have both been scenarios in which the agents happened to also be responsible for the silence in the first place. In the following section, I address the question of blameworthiness and the context of suppression.

\section{The circumstances of silence}

When we assess whether an agent is blameworthy, and exactly what they are blameworthy for, it is important not just to have an account of what an appropriate reaction to silence is, but also of how blameworthiness is connected to the circumstances in which that silence arose. There are at least four possible scenarios here, and depending on which scenario the agent finds herself in, this will impact on whether she is blameworthy and what she is blameworthy for. They are (in order of what I suspect is increasing culpability): 
1) The agent did not suppress the disagreement, and she could not reasonably have been expected to know about the existence of the disagreement, or that the disagreement had been suppressed (e.g. silence in apparently normal conditions).

2) The agent did not suppress the disagreement, but there were cues that should have alerted her to the suppression (e.g. there was silence in a context where one would have ordinarily anticipated debate). That is, there were aspects of the context that were relevant to the assessment.

3) The agent suppressed the disagreement, but she did not know that she had suppressed the disagreement (perhaps she is oblivious to how frightening her peers find her), but there were cues that should have alerted her to the suppression (e.g. there was silence in a context where one would have ordinarily expected there to be debate).

4) The agent suppressed the disagreement and she knew that she had suppressed the disagreement (e.g. she is an Idi Amin-esque dictator who kills those who disagree with her, but it might not be as extreme as in this example suggests - intentional side-lining in politics would be sufficient). ${ }^{6}$

I take it the agent in scenario 1) is obviously not culpable for her ignorance, while the agent in scenario 4) is obviously culpable. The agents in scenarios 2) and 3) are more complicated

The agent in 2) will not be culpable for the circumstances of the suppression, but will still be culpable for her ignorance if she failed to pick up on the silence that was masking the suppressed disagreement (assuming the silence was unusual in that context, and assuming that her role was such that she should have been paying attention for such markers). ${ }^{7}$ The agent in 3) will be responsible for her ignorance if she failed to pick up on the cues (again, assuming relevant role and context). Additionally, she may also be blameworthy for the circumstances of the suppression (Tanesini, 2016). For instance, perhaps the agent is arrogant, and it was her arrogance that suppressed the disagreement. Under these

\footnotetext{
${ }^{6}$ Thanks to Jonathan Birch for suggesting these four scenarios to me.

${ }^{7}$ If the agent has a cognitive impairment that limits their ability to detect normal social cues, then that might count as an excuse on their part and get them off the hook. But for most agents, it is reasonable to expect them to be sensitive to ordinary social cues.
} 
circumstances she might also be blameworthy for the epistemic injustice inflicted on those who were silenced (Fricker, 2007). Both the Mbeki and the Tyrannical Dictator cases are those in which the agent is responsible both for ignoring the markers of suppression, and for creating the suppression. However, there are other cases in which the agent is not responsible for the suppression, but may still be responsible for not picking up on its markers.

\section{Conclusion}

In this paper I have looked at agents who might appeal to ignorance as an excuse in cases of suppressed disagreement. Agents can appeal to excuses from ignorance for actions that would be otherwise blameworthy, but an excuse from ignorance will only succeed if the ignorance is not culpable. Culpable ignorance can be avoided by satisfying one's procedural epistemic obligations, and one way to do this is by paying attention to peer disagreement. But what happens in situations of suppressed disagreement, such as the cases of the Tyrannical Dictator and Mbeki? That is, situations in which there was no disagreement forthcoming, but only because of suppression.

One response to cases of possible disagreement has been to argue that they show that the testimonial act of asserting disagreement is irrelevant. Rather it is the reasons and evidence that could be put forward in support of disagreement that matters. That is, merely possible agreement should count. However, giving merely possible disagreement consideration has some strange implications. It leads us into untenable scepticism, and it fails to recognise that the reason we pay attention to actual disagreement is because it signals potential errors. Merely possible disagreement does not provide the agent with information, and it is too much to expect that ordinary epistemic agents should anticipate all possible objections to their views. Instead, I argue that the distinction should not be between 'actual disagreement' and 'merely possible disagreement', but rather it should be between 'expressed disagreement' and 'suppressed disagreement'. Unlike cases of merely possible disagreement, in which the agent gets no new information, being confronted with the stony silence often associated with suppressed disagreement can give the agent information (depending on the context and the role ocff the agent in that context). For instance, unusual 
silence in response to an assertion (such as in a political context) should indicate to the agent that all is not well.

When we assess an agent's claim to ignorance as an excuse for an otherwise blameworthy action, checking whether they satisfied their procedural epistemic obligations would thus involve not only checking that they had paid attention to expressed disagreement from their epistemic peers, but would also that they were appropriately sensitive to the markers of suppression. Further, the agent might also be responsible for the circumstances of suppression, and can be held additionally blameworthy for that.

Acknowledgements. Thanks to Luc Bovens and Katie Steele for feedback on earlier drafts of this paper, and to Erin Nash for extensive discussion on this topic and written comments. Thanks also to two anonymous referees from this journal who gave very detailed help and advice, and to audiences from Choice Group at the London School of Economics, and the Institute of Future Studies in Stockholm. 


\section{Bibliography}

Anonymous. (2002, March). Castro Hlongwane, caravans, cats, geese, foot \& mouth and statistics: HIV/AIDS and the struggle for the humanisation of the African.

Aristotle. (1999). Nichomachean Ethics. (T. Irwin, Trans.) Indianapolis/Cambridge: Hackett Publishing.

Ballantyne, N (2014) Counterfactual Philosophers. Philosophy and Phenomenological Research, 368- 387.

Ballantyne, N. (2015). The Significance of Unpossessed Evidence. The Philosophical Quarterly, 1-21.

Barnett, Z. \& Li, H (2016) Conciliationism and merely possible disagreement. Synthese. pp. 1-13.

Beatty, J., \& Moore, A. (2010). Should we aim for consensus? . Episteme, 198-214.

Carey, B. (2011 ). Possible disagreements and defeat. Philosophical Studies, 371-381.

Christensen, D. (2007 ). Epistemology of Disagreement: The Good News . The Philosophical Review , 187-217.

Dryzek, J., \& Niemeyer, S. (2008). Discursive Representation. American Political Science Review, 481-493.

Durban Declaration. (2000, July 6). The Durban Declaration. Nature , 406, pp. 15-16.

Elga, A. (2007). Reflection and Disagreement. Nous, 478-502.

Elster, J. (1986/1997). The Market and the Forum: Three Varieties of Political Theory . In J. Bohman, \& W. Rehg, Deliberative Democracy (pp. 3-34). Cambridge, MA: MIT Press .

Feinstein, A. (2007). After the Party: A Personal and Political Journey inside the ANC. Jeppestown: Jonathan Ball Publishers.

Feldman, R. (2006 ). Epistemological Puzzles about Disagreement. In S. Hetherington, Epistemology Futures (p. 223). Oxford: Oxford University Press.

Fischer, J., \& Ravizza, M. (1998). Responsibility and Control: A Theory of Moral Responsibility. Cambridge: Cambridge University Press.

Fricker, M. (2007). Epistemic Injustice: Power and the Ethics of Knowing. Oxford: Oxford University Press.

Goldberg, S. (2017). Should have known. Synthese, 2863-2894.

Goldberg, S. (2016). Arrogance, Silence and Silencing. Aristotelian Society Supplementary Volume, 94-111.

Herbst, J. (2005). Mbeki's South Africa. Foreign Affairs, pp. 93-105.

Johnson, R. (2007, December 7). The Native Paranoia od Thabo Mbeki. Wall Street Journal, p. A24.

Kelly, T. (2005). The Epistemic Significance of Disagreement. In Oxford Studies in Epistemology, 1 (pp. 167-196).

Kornblith, H. (2010). Belief in the Face of Controversy. In T. Warfield, \& R. Feldman, Disagreement (pp. 29-52). New York: Oxford University Press .

Lammenranta, M. (2011). Skepticism and Disagreement. In D. Machuca, Pyrrhonism in Ancient, Modern, and Contemporary Philosophy (pp. 203-216). Dordrecht: Springer.

Langton, R., \& West, C. (1999). Scorekeeping in a Pornographic Language Game. Australasian Journal of Philosophy, 303-319.

Levy, N. (2005). The Good, the Bad and the Blameworthy. Ethics and Social Philosophy, 1-16. Longino, H (1990) Science as Social Knowledge: Values and Objectivity in Scientific Enquiry. Princeton, Princeton University Press 
Nattrass, N. (2008). AIDS and the Scientific Governance of Medicine in Post-Apartheid South Africa . African Affairs, 157-176.

Peels, R. (2017) Responsible Belief: A Theory in Ethics and Epistemology. Oxford University Press: New York.

Rosen, G. (2004). Skepticism about Moral Responsibility . Philosophical Perspectives , 295313 .

Sidgwick, H. (1981/1907). The Methods of Ethics (Hackett first edition, unabridged republication of the seventh (1907) Macmillian edition ed.). Cambridge: Hackett.

Steinberg, J. (2017, January ). A Taste for Medicine: Re-examining the early years of antiretroviral treatment in South Africa. African Affairs .

Strawson, P. (2008). Freedom and Resentment and Other Essays. New York: Routledge.

Tanesini, A. (2016). 'Calm Down Dear': Intellectual Arrogance, Silencing and Ignorance. Aristotelian Society Supplementary Volume, 71-92.

Tersman, F. (2013 ). Moral Disagreement: Actual vs. Possible. In D. Machuca, Disagreement and Skepticism (pp. 90-108). New York: Routledge.

Williams, B. (1981 ). Moral Luck: Philosophical Papers 1973-1980. Cambridge : Cambridge Universiy Press .

Zimmerman, M. (1997). Moral Responsibility and Ignorance. Ethics, 410-426. 